\title{
Pedro e Jorge Reinel (at.1504-60)
}

Dois cartógrafos negros na côrte de d. Manuel de Portugal (1495-1521)

Pedro and Jorge Reinel (at.1504-60). Two black cartographers in the court of d.

Manuel of Portugal (1495-1521)

Pedro et Jorge Reinel (at.1504-60). Deux cartographes noires dans la cour de D.

Manuel de Portugal (1495-1521)

Pedro y Jorge Reinel (at.1504-60). Dos cartógrafos negros en la corte de d. Manuel de Portugal (1495-1521)

\section{Rafael Moreira}

\section{(2) OpenEdition}

\section{Journals}

Edição electrónica

URL: https://journals.openedition.org/terrabrasilis/1209

DOI: 10.4000/terrabrasilis. 1209

ISSN: 2316-7793

Editora

Rede Brasileira de História da Geografia e Geografia Histórica

Refêrencia eletrónica

Rafael Moreira, «Pedro e Jorge Reinel (at.1504-60)», Terra Brasilis [Online], 4 | 2015, posto online no dia 13 fevereiro 2015, consultado o 05 dezembro 2022. URL: http://journals.openedition.org/terrabrasilis/ 1209 ; DOI: https://doi.org/10.4000/terrabrasilis.1209

Este documento foi criado de forma automática no dia 5 dezembro 2022.

All rights reserved 


\section{Pedro e Jorge Reinel (at.1504-60)}

Dois cartógrafos negros na côrte de d. Manuel de Portugal (1495-1521)

Pedro and Jorge Reinel (at.1504-60). Two black cartographers in the court of $d$. Manuel of Portugal (1495-1521)

Pedro et Jorge Reinel (at.1504-60). Deux cartographes noires dans la cour de D.

Manuel de Portugal (1495-1521)

Pedro y Jorge Reinel (at.1504-60). Dos cartógrafos negros en la corte de d. Manuel

de Portugal (1495-1521)

\section{Rafael Moreira}

1 Na $1^{a}$ fase da expansão marítima pelo Oceano, os navegadores portugueses descobriram, mediram e cartografaram as Ilhas Atlânticas e a costa ocidental africana para sul de Marrocos. Em 1460, o ano da morte de seu principal instigador Infante D. Henrique, eles atingiam a embocadura da Serra Leoa (Sierra Leone) -"um dos lugares mais agradáveis do mundo para se viver", na opinião do geógrafo Elysée Reclus (1885) -, onde fundaram numa ilha à entrada da floresta uma feitoria e um forte para o comércio do ouro e produtos do sertão (ou "desertão": o Saara), estabelecendo relações muito cordiais com a população local: as aldeias de negros da etnia Wolof (Jalofos), altos, de feições finas, amigáveis, inteligentes, muito interessados por tudo - concretamente, os Sapés, que os Portugueses julgavam serem "Etíopes", súditos do imperador Preste João das Índias (que seriam exterminados c.1540 pela invasão dos Mendés, tribos vindas do interior, e reduzidos a algumas comunidades nas ilhas Sherbro, completamente desestruturados). Segundo a mitologia Sapé, seus mortos viviam sob o mar, brancos como peixes, e voltariam um dia para visitá-los montados numa grande ave marítima - motivo pelo qual acolheram tão bem os Portugueses e seus navios.

Exímios no talhe do marfim - assim como da madeira e pedra-sabão em que esculpiam os ídolos ou imagens de culto dos antepassados que colocavam à entrada de suas casas -, começaram imitando pequenos objetos que os Portugueses traziam nas caravelas: primeiro talheres (colheres de estanho, garfos, cabos de facas); depois saleiros e os chamados "olifantes", ou roncas, trompas de metal que serviam para assinalar a posição dos barcos em dias de nevoeiro; e, por fim, encomendas de peças mais elaboradas, 
verdadeiras obras-primas, copiadas de modelos e desenhos trazidos de Portugal. Assim se criou c.1470-80 o primeiro foco de sincretismo estético extra-europeu desde a Antiga Roma: a arte designada "afro-portuguesa" (W. Fagg, 1959), que seria a nosso ver mais corretamente chamada sapé-manuelina. Foi um episódio com uma duração de pouco mais de meio-século, e de que apenas se conhecem cerca de 200 a 300 exemplares: a maior parte terá desaparecido devido à sua extrema fragilidade, ou está ainda por identificar em museus e coleções estrangeiras. Mas chamou a atenção da Literatura de Viagens da época: em 1506 o nauta Duarte Pacheco Pereira afirmava que "nesta terra se fazem as mais sotis colheres de marfim e melhor lavrado que em nenhua outra parte"; e em 1508 o comerciante alemão estabelecido em Lisboa Valentim Fernandes escrevia que "em Serra Leoa os homens são mui sutis e engeniosos, e fazem em marfim qualquer obra de que lhe dão o debuxo (desenho)" - entendendo-se por "sutis" a refinada elegância, que chega a lembrar o Antigo Egito, e extraordinária perícia técnica.

Devido ao monopólio real do marfim após 1481, os artesãos mais hábeis foram trazidos para Lisboa como escravos régios - um alto status social -, vivendo e trabalhando numa oficina no Palácio e se casando com criadas da côrte, em convívio e familiaridade com o próprio Rei. Só assim foi possível fazerem-se em dois meses as muitas dezenas de peças (hoje espalhadas pelos melhores museus do mundo: de Camberra à Fundação Walt Disney!) levadas por D. Manuel I em 1498 para Espanha ao ser jurado sucessor dos Reis Católicos, a fim de as oferecer aos sogros e a nobres como símbolos exóticos do seu papel de "Dominus Mundi". São peças híbridas, de ornato, material e mão-de-obra africanos, mas com formas, função e iconografia típicas do estilo manuelino.

Pela análise comparativa, o especialista italiano da arte afro-portuguesa Ezio Bassani conseguiu, quando da primeira exposição em Nova York, no Center for African Art, em 1988 (Africa and the Renaissance. Art in Ivory, Prestel-Verlag) individualizar 9 mãos de artistas bem diferenciados trabalhando numa mesma oficina, que ele imaginou na África, mas hoje não temos qualquer dúvida em situar no próprio Paço Real da Alcáçova, em Lisboa (no alto frente ao Castelo de S. Jorge, ruído com o Terremoto de 1755), ou no Paço da Ribeira a partir de 1504, quando ele se tornou habitável.

5 Também a origem destes artistas é controversa. Bassani, seguindo aliás a opinião de Fagg e da maior parte dos especialistas africano-americanos (Katty Curnow, Paula BenAmos, Susan Vogel), considera dois focos muito distantes: Serra Leoa e o antigo Reino do Benim. Mas, após a série de estudos recentes do norte-americano Peter Mark, podemos afirmar com segurança que o Benim nunca produziu marfins trabalhados sob encomenda portuguesa e que a sua primeira e única origem - de obras e artistas trazidos para Portugal - reside na vasta enseada de Serra Leoa.

6 Eram delicadas obras de aparato e alto luxo para serem usadas em desfiles e cerimónias - banquetes e batizados nobres, como os "saleiros", que não serviam de baixelas de mesa (inexistentes na época) mas sim para o padrinho de alta nobreza transportar nos seus dois recipientes côncavos a água-benta e os grãos de sal a fim de serem colocados pelo oficiante na língua do infante, como se vê nalguns quadros - ou destinadas ao uso dos jovens príncipes (o Hermitage de São Petersburgo possui um olifante com a legenda esculpida "Inf. D. Luís", filho do rei D. Manuel que teria então pouco mais de 10 anos!) Conforme pude há pouco demonstrar, o rei D. João III - e decerto já seu pai D. Manuel dispunha de uma guarda pessoal de corpo, que sempre o acompanhava, composta de 50 negros (certamente da Serra Leoa) trazendo a tiracolo uma ronca - o erradamente designado de "olifante", ou trompa de caça, pela historiografia - em marfim esculpido 
pintado a ouro. Uma demonstração de poder única na Europa. O que mais surpreende, é a capacidade do artista/artesão negro visualizar o desenho bidimensional num complexo de formas e volumes em três dimensões, que se interpenetram, enlaçam, sobrepõem, torcem ou juxtapõem segundo os princípios compositivos típicos do estilo manuelino, do mais extremo naturalismo, em conjuntos vibrantes de vida, dinamismo e interacão: o soldado luso fumando seu cachimbo, velhos comerciantes de longas barbas, um português montado a cavalo, grupos de mulheres de mãos dadas alternando com animais. Cordas, entrançados, fios de pérolas, nós - os famosos "nós" manuelinos -, esferas armilares, cenas de caçadas, javalis, cervos (animais que não existem na África), faixas torcidas, inscrições em português e latim, o brasão de armas com a divisa do rei D. Manuel e de nobres, cruzes-de-Cristo, formam o essencial da decoração, que não se diferencia muito da dos monumentos portugueses da época e copia à letra gravuras de livros de oração, como as Horae Beatae Mariae Virginis (Paris, 1496, trad. port. 1498), que todo o capitão levava consigo em suas viagens, que duravam meses.

7 Talvez do melhor desses artífices anónimos e chefe do ateliê do Paço, o habilidosíssimo "Mestre das Armas de Castela e Aragão" como o designou Ezio Bassani, fosse filho nascido c. 1480 - o menino negro ou mulato baptizado com o nome de Pedro, que viria a adoptar o apelido de Reinel, ou reinol (isto é, "nascido no Reino"), que lhe ficaria como sobrenome de família. Educado no Paço, recebeu a esmerada instrução dos cortesãos, que soube juntar à técnica tradicional do pai, unindo a maestria na arte do "debuxo" aos mistérios das matemáticas e da cosmografia; e, esperto e precoce, viria a tornar-se num dos maiores cartógrafos da côrte do rei D. Manuel, cujo ambiente absorveu como poucos: foi ele Pero ou Pedro Reinel.

8 Enquanto o pai nascera na distante Serra Leoa, noutro continente, ele tinha já nascido em Portugal, e orgulhava-se disso. 0 sobrenome Reinel não é único na época, mas em casos isolados e que nunca chegaram a constituir uma linhagem, que não figura nos livros de genealogia. Maria Teresa Schedel Castelo-Branco, no seu trabalho A origem dos Reineis (1996), imagina uma família com origem no final do século XIII num francês Mestre Rainier e elenca uma dezena de Reinéis entre 1443 e 1563 - mas todos eles são naturais de Marrocos (Azamor, Safim) e deviam ser filhos de Mouros cristãos que adotaram o nome por haverem nascido no Reino. Era-se, pois, um fenômeno vulgar. 0 ateliê dos eburnistas trazidos da Serra Leoa se localizava no próprio Paço, decerto paredes-meias com a oficina régia de Cosmografia, onde um grupo de cartógrafos estudava, executava e arquivava os mapas oficiais da Coroa. O jovem Pedro desde criança deve ter sido deslumbrado por essas artes, atraído por sua habilidade no desenho e pela curiosidade em conhecer os segredos das rotas e costas que o separavam da terra de origem do pai. Aí deve ter recebido as primeiras lições da ciência da Cartografia, ao mesmo tempo em que na aula dos filhos dos criados palacianos estudava gramática, rudimentos de latim, matemáticas e a "Esfera" ou cosmografia e geografia. Uma formação apurada, que a sua inteligência tornou excepcional, e justifica que pelos 20 anos fizesse o cobiçado exame para "mestre das cartas de marear", em que ao longo da vida realizaria uma notabilíssima obra ao serviço da Coroa de Portugal, sendo ele próprio sempre designado como português.

9 Saíram de suas mãos, só ou junto com seu filho Jorge Reinel, 9 mapas (hoje conhecidos) datáveis de até c.1540, que estão entre as grandes obras da cartografia manuelina: nomeadamente o célebre "Atlas Miller" (1519) - o "mais belo atlas do mundo" associado à viagem de circum-navegação de Fernão de Magalhães, cuja costa do Brasil é 
ilustrada por preciosas iluminuras pintadas por António de Holanda, o rei-de-armas e miniaturista heráldico de D. Manuel, pai de Francisco de Holanda (A. Pinheiro Marques). E a mais antiga carta náutica que se conhece de Pedro, hoje datada por Ferreira do Amaral de 1504, é a primeira do mundo a conceptualizar um sistema de projeção cartográfica em escala de latitudes graduada por um "tronco de léguas", superando os meros roteiros-portulanos medievais - o que mostra os seus conhecimentos e saber técnico e teórico fora do comum.

10 A origem africana de Pedro Reinel - que num mapa do Atlântico de 1504, orgulhosamente assinado (Archives Départementales de la Gironde, Bordéus), coloca numa bandeira na Serra Leoa um ídolo de marfim em homenagem a seus antepassados, e mais abaixo uma leoa gigante - o único animal representado em todo o mapa - a segurar com uma pata a bandeira do Reino, assim engrandecendo o lugar de origem do pai... - prova que o Portugal quinhentista ignorava qualquer tipo de racismo, como tão bem intuíu Gilberto Freyre. 0 gosto pelo abuso de bandeiras, flâmulas e faixas de pano muito coloridas é, aliás, característica do seu estilo de cartografar (a carta citada apresenta nada menos de 26 bandeiras!), de um tom bem africano. 0 que não passaria de um fait-divers, se não se desse a circunstância de Pedro Reinel ter sido feito "moçode-esporas de el-rei" - o primeiro grau da baixa nobreza, que se atingia pelos 14/15 anos de idade - e ainda jovem ter visitado o seu país: foi enviado cerca de 1495 numa embaixada ao reino do Mali, até Tombuctu (decerto como intérprete); e foi o único que escapou com vida, segundo refere o cronista João de Barros, "por ser homem costumado andar naquelas partes". Aí recolheu notícias locais sobre o interior do Saara e as fontes do Nilo, bem como as mais rigorosas informações geográficas - rios, lagos, montes - e dados que fornece sobre o traçado da costa: um processo que irá repetir na imagem que dá do "Novo Mundo", face à do planisfério dito de Cantino, o primeiro mapa a representar o Brasil (1502).

11 A negritude de Pero (ou Pedro) e seu filho Jorge Reinel resulta fora de quaisquer dúvidas de dois textos conhecidos e publicados desde há muito (Sousa Viterbo, 1906), mas só recentemente lidos na sua integridade - pois o papel apresenta uma lacuna difícil de ser lida no exato ponto em questão e foi transcrito com essa linha substituída por pontos, até ser corretamente interpretado. Com essas falhas foram sempre reproduzidos (Denucé, 1908 - que nem sequer transcreve as linhas em dúvida -; Armando Cortesão, 1935; J. Ferreira do Amaral, 1995, que assinala a omissão mas não procura preenchê-la), até os documentos originais serem relidos pelo especialista Alfredo Pinheiro Marques na sua edição facsimilada do "Atlas Miller" (Barcelona, Moleiro Editor, 2006) e transcritos na íntegra. Trata-se de duas cartas, escritas por altos funcionários das duas côrtes ibéricas - a do rei D. João III e a de seu cunhado, o imperador Carlos V -, no âmbito da Junta de Badajoz-Elvas, que se reunira em 1523-4 para resolver o essencial problema geopolítico da exata localização, face à linha de Tordesilhas, do arquipélago das Molucas (atual Indonésia), na sequência da viagem de circum-navegação do globo pelo português Fernão de Magalhães ao serviço da Espanha.

12 A primeira, redigida em código (que Cortesão conseguiu decifrar), conserva-se no Arquivo Geral de Simancas; data de Badajoz, aos 29 de Agosto de 1523, e é da mão do embaixador castelhano em Portugal, Zúñiga, dirigida secretamente a Carlos V. Segundo o texto editado por Pinheiro Marques, ele tinha conseguido à custa de corrupção do departamento oficial de cartografia do rei de Portugal, em Lisboa, "una carta entera de 
toda la navigación" - que era segredo de Estado -, e "le acaban esta semana una otra en libro, el que hace las (mapas) del rey de Portugal, que se llama Lopo Homem, este y un negro. Residen en Lisboa, y tienen orden de no hacer cartas para nadie sino para el rey, pero algunas veces se atreven con dinero $y$ con seguridad, aunque sea muy dificultoso." Era a equipe que tinha acabado de fazer o espetacular "Atlas Miller", sob a supervisão geral e assinatura de Lopo Homem - o nobre diretor do departamento de Cartografia, socialmente mais prestigiado -, porém na verdade executado por Pedro Reinel com a colaboração de seu jovem filho Jorge. Mas A. Cortesão, levado pelos preconceitos raciais da sua época, nos anos 60, limita-se a um simples comentário, de passagem: "Segundo parece, Lopo Homem teria um ajudante negro para o seu trabalho cartográfico"; e nada adianta sobre o assunto. Não lhe ocorreu que nestes trabalhos de alto segredo de Estado não existiam meros ajudantes anônimos, e afastou o dado como um casual pormenor lateral e fortuito, partindo do princípio de que, se se tratava de "um negro", não poderia passar de um qualquer auxiliar... Mas o contexto é bem claro: o "negro" que colaborava com Lopo Homem - e que, aliás, era o principal autor dos desenhos, visto que Homem se limitava a supervisá-los, como se vê claramente do "Atlas Miller" - não era outro senão o cartógrafo Pero, o patriarca da cartografia manuelina portuguesa, de origem étnica africana, e por isso conhecido apenas como "o negro", face ao seu aristocrático chefe, o interlocutor do diplomata Zúñiga, que mal devia conhecer Pedro Reinol, ou Reinel.

O que não significa que este fosse um desconhecido da documentação oficial. Em 1519, o feitor de Portugal na Andaluzia afirmava ao rei D. Manuel que eu vi assentadas (as ilhas Molucas) na poma (globo terrestre) e carta que cá fez o filho de Reinel para uso na viagem clandestina de Fernão de Magalhães, mas que o pai fora lá buscá-lo - a Sevilha, onde se refugiara após uma briga de jovem - e as trouxe, sendo perdoados. De facto, por carta régia de 10 de Fevereiro de 1528, já D. João III concedia a Pedro Reinel, "criado de elrei" (título superior ao de moço-das-esporas) e "mestre de cartas e agulhas de marear em meus Reynos e senhorios", a tença ou salário anual de 15 mil reais, sendo seu filho Jorge em 1532 nomeado como "escudeiro da Casa Real" com licença para porte de armas e uma tença de 10 mil reais; em 1534 Pedro recebia uma tença graciosa de $15 \mathrm{mil}$ reais, e seu filho de 20, decerto por algum trabalho extra; em 1542 a mulher de Pedro Reinel, "que faz cartas de marear", Isabel Fernandes, fazia uma denúncia à Inquisição, o que indica posição de certo prestígio junto das autoridades; de 1551 a 1564, sem dúvida após o falecimento do pai, Jorge Reinel presidia a exames para o lugar de mestre de cartografia; e em 1572 sua mulher, Brites Lopes, era perdoada da suspeita do desvio de certas porcelanas por ele, já cavaleiro da casa del-rei, ser "velho e doemte". Eram, pois, funcionários da Casa Real que se podem considerar com uma carreira razoavelmente bem documentada.

14 A segunda carta foi escrita de Elvas a 9 de Junho de 1524 ao novo monarca português, em grande segredo, pelo jurista Antônio Azevedo Coutinho, delegado à Junta BadajozElvas, comunicando-lhe que Pedro Reinel (que se encontrava então no local para acompanhar as negociações técnicas) o informara de que tanto ele como seu filho tinham sido abordados por um colega castelhano para passarem ao serviço da Espanha, e insistentemente atraídos por cartas assinadas pelo próprio punho do imperador Carlos V! Pedia instruções ao Rei sobre o que fazer; e prendeu o cartógrafo espanhol, revistando-o e encontrando as comprometedoras cartas do Imperador - que provocaram uma total reviravolta nas conversações -, graças à denúncia patriótica de Reinel. o próprio Joaquim Ferreira do Amaral, na sua excelente biografia e estudo da obra do cartógrafo (Pedro Reinel me fez, Lisboa, Quetzal Editores, 1995, como ele assina 
um de seus mapas), passa por cima deste crucial episódio em apenas um parágrafo, limitando-se a assinalar as lacunas do documento e sem se aperceber de todo o seu alcance.

Nesta assombrosa carta, em que o delegado afirma que Pedro Reinel lhe havia confessado que seu filho Jorge recebera do Imperador um agrado de 30 mil reais, lê-se nas últimas linhas uma proposta reveladora: que D. João III finja consentir que os Reineis executem trabalhos para Carlos V mas errados, para enganá-lo em manobra de contra-espionagem; e "com astucia lhe mandará estes negros e outros mui melhores mestres do que eles" (devia estar-se a referir a Lopo Homem e seu filho Diogo, da influente família de cartógrafos nobres, os Homens, cuja irmã era casada com António de Holanda e mãe do artista-cortesão Francisco de Holanda).

Somente a partir da $2^{a}$ metade do século XVII a palavra "negro" ganha, em Portugal, um sentido pejorativo: de primitivo, rude, selvagem em baixo da escala social, ou mesmo fora dela. Para os viajantes ingleses dos séculos XVIII e XIX, os portugueses eram "os negros" da Europa, numa acepção mais cultural e social de não-civilizados do que estritamente rácica. Em 1524, eram negros simplesmente os de pele escura com origem africana - como se vê da pompa e respeito com que D. João II recebeu em 1488 a embaixada do rei Bemoim dos Jalofos do Senegal, baptizado com o nome de João, tratado por "irmão", e com quem estabeleceu uma aliança -, embora a palavra fosse também aplicada a qualquer homem escuro não-europeu: indianos do Sul, índios brasileiros... Eram os "estranhos", no sentido de simples estrangeiros de pele negra. Não existia, não se conhecia traço algum de racismo. Graças a esta extraordinária revelação, ficamos a saber que os famosos Reineis - nas palavras de Alfredo Pinheiro Marques, "os mais antigos e importantes cartógrafos do início dos descobrimentos geográficos e da expansão colonial portuguesa e europeia" - tinham origem étnica africana e pele e feições negras. $O$ que não obstou a que, graças ao seu talento, Pedro singrasse na profissão e fosse acolhido como cortesão no próprio palácio real, passando de filho de um escravo a homem livre, e com uma carreira nobilitada no seio palaciano.

Pela nossa parte, julgamo-lo filho do mais hábil artesão de marfim - esse material exclusivo de imperadores, como o Preste-João da Etiópia, de onde os julgavam naturais - trazido da Serra Leoa para Portugal nas últimas décadas do século XV e que aqui estabeleceu oficina no próprio paço, onde realizou algumas das obras-primas de maior luxo e propaganda da arte manuelina, casou, aculturou-se, e teve um filho - chamado de Reinel ou "reinol" por ser já nascido no Reino - que lhe seguiu as pisadas no domínio da técnica do debuxo e do desenho, aliado à formação cultural e instrução em matemáticas e cosmografia que recebeu nas aulas da côrte. Tendo passado talvez parte da infância na aldeia paterna da costa serra-leonesa, o jovem Reinel teve ocasião de recolher e obter informações in-loco sobre o ignoto sertão do continente, que ao regressar incorporou a seus mapas. Ainda era vivo em 1542, conhecendo-se dele (só, ou em parceria com o filho) o Atlas e 6 mapas - 2 dos quais assinados em boa caligrafia - e mais 3 só de Jorge Reinel, ainda vivo em 1562.

17 Curioso é que no mais antigo desses mapas que conhecemos, hoje datado de 1504, Pedro Reinel sobrepõe no mesmo espaço duas linhas do litoral africano - por falta de espaço? por só mais tarde ter tido conhecimento da sua continuação? eram as duas hipóteses até agora aceites... -: uma na continuação do mapa da Europa ocidental ao Norte de África até à costa da Mina (datável de 1498), onde se vê no lugar da Serra Leoa a eloquente bandeira com o rosto de um ídolo de marfim; e outra mais para o interior, 
prolongando a costa pelo Golfo da Guiné até à foz do rio Zaire ou Congo (de 1504), descoberto desde 1483 por Diogo Cão. Como explicar esse intervalo temporal e estranha dualidade de perfis? Na recente e engenhosa hipótese de Ferreira do Amaral, o cartógrafo não fez mais do que obedecer criteriosamente à proibição de D. Manuel de se representar a costa de África para além do Castelo da Mina - a mais antiga fundação europeia na zona tropical, erguido em 1483 (atual Elmina, no Ghana) -, sob pena da perda de todos os seus bens, alargada por alvará de 13 de Novembro de 1504 até à foz do rio Congo.

A que nos permitimos acrescentar: não querendo deixar vago o interior do continente a Sul do Saara por falta de informações fidedignas, preferiu retomar seu velho mapa de mais de 5 anos e preencheu o espaço vazio com a representação autorizada da linha costeira até ao Congo - um horror vacui que explica, a nosso ver, a insólita sobreposição de linhas de costa e a posterior inserção de nada menos de 10 bandeiras coloridas, 8 das quais com o crescente muçulmano.

É a mesma preocupação com uma representação rigorosa do interior, desse "sertão" misterioso e inacessível, que encontramos em toda sua produção cartográfica: em particular na do Novo Mundo do Brasil, uma das mais belas das 26 páginas in-folio do álbum conhecido por "Atlas Miller". Aí, terá sido dialogando com os primeiros Tupinambás trazidos em 1500 de Porto Seguro, acolhidos e aculturados na côrte - como o que se vê bem representado sob a forma de Rei Mago no retábulo da Sé de Viseu (c. 1502): de porte altivo, usando gibão de seda acolchoada com mangas de amplas fitas soltas, jóias, calção de algodão aveludado, tal como o pintor flamengo Francisco Henriques (e não o Grão-Vasco, ou Vasco Fernandes, como se pensava) o terá visto em alguma festa - que Pedro Reinel pode ter obtido notícias seguras a respeito dos rios, lagos e montes interiores, de minas e da fauna, que ele cartografa com grande segurança e realismo. $O$ seu cuidado com a representação do interior do país vai ao ponto de, seguindo a notícia dos índios, mostrar 2 grandes rios - decerto o Amazonas (que confunde com a baía do Maranhão) e o Paraguai - partindo de um lago no centro: o fabuloso El Dorado, podendo-se assim considerá-lo o pioneiro na criação do mito da "Ilha-Brasil" que se iria manter até ao fim do século XVIII (Jaime Cortesão).

Foi graças a esse cosmopolitismo e ausência de preconceitos rácicos na côrte de D. Manuel I, onde conviviam e trocavam informações mouros com eslavos e nórdicos, índios do Brasil com negros da Senegâmbia e Congo, judeus, indianos, malaios, jaus, e até algonquinos da América do Norte e do Canadá (uns 57 vindos em 1502), que a Cartografia portuguesa pôde obter em primeira mão uma vista mais detalhada do mundo e do Brasil - de que o Atlas Miller elenca 150 topónimos, contra 50 em média nas outras regiões. São a mais realista visão do globo terrestre na Europa do seu tempo, além de verdadeiras obras-de-arte, que constituem um pioneiríssimo - e excepcional, senão único - testemunho de mestiçagem étnica, de interesse geográfico universal, e de um intenso carácter de hibridismo estético, que torna a ciência de "fazer mapas" um autêntico exercício artístico. 
Pedro Reinel, mapa do Atlântico Leste, assin. Pedro Reinel me fez

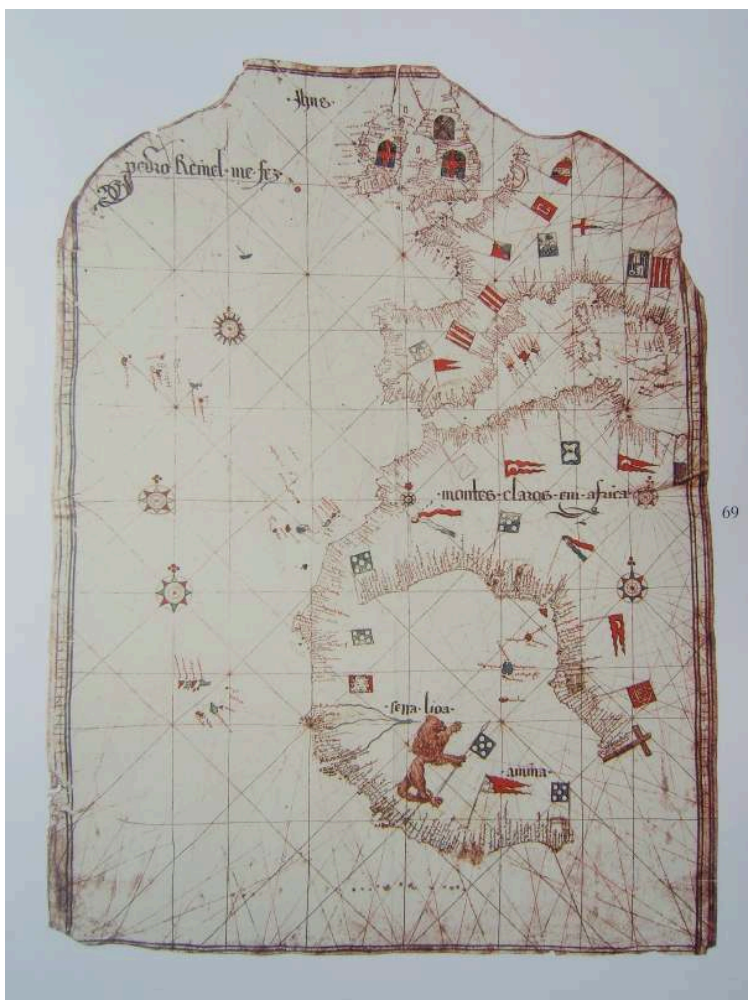

1498?-1504. PERgAMINHO, 71 x 95 CMS.

ARCHIVES DÉPARTEMENTALES DE LA GIRONDE, BORDÉUS 
"Mestre das Armas de Castela e Aragão"

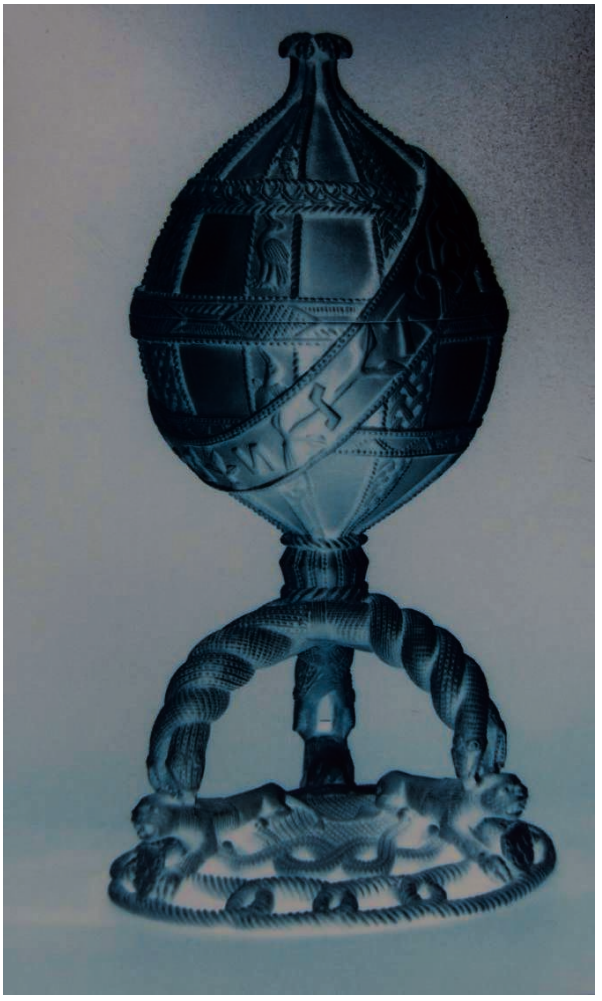

SALEIRO DE DUAS CAVIDADES EM FORMA DE ESFERA ARMILAR. MARfiM, 21 CMS. MUSEUM FÜR VÖLKERKUNDE, BERLIM 
Rosto de moço-de-esporas negro (Serra Leoa ou Mina) sentado aos pés do seu senhor

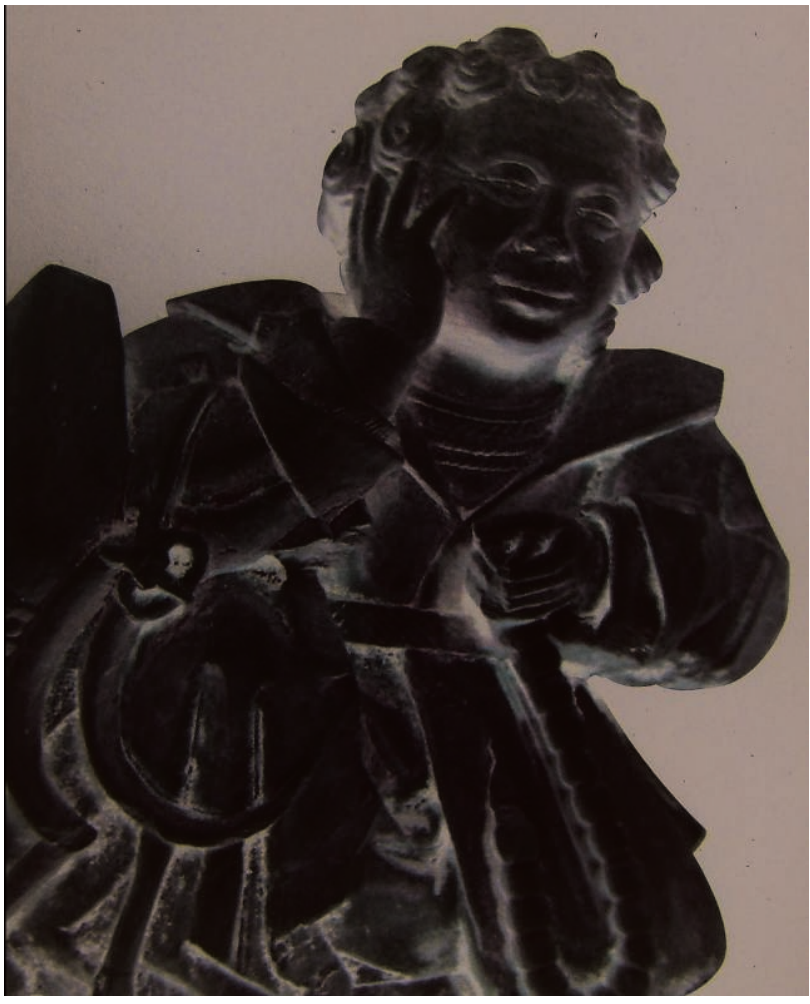

TÚMULO EM CALCÁRIO de dIOgO dE AZAMBUJA, FUNDADOR DO CASTELO DA MINA, C.1515 MONTEMOR-O-VELHO, IgREJA DE ${ }^{\mathrm{a}}$ SR $^{\mathrm{a}}$ DOS ANJOS.

Orquestra de negros no balcão de uma sala de festas

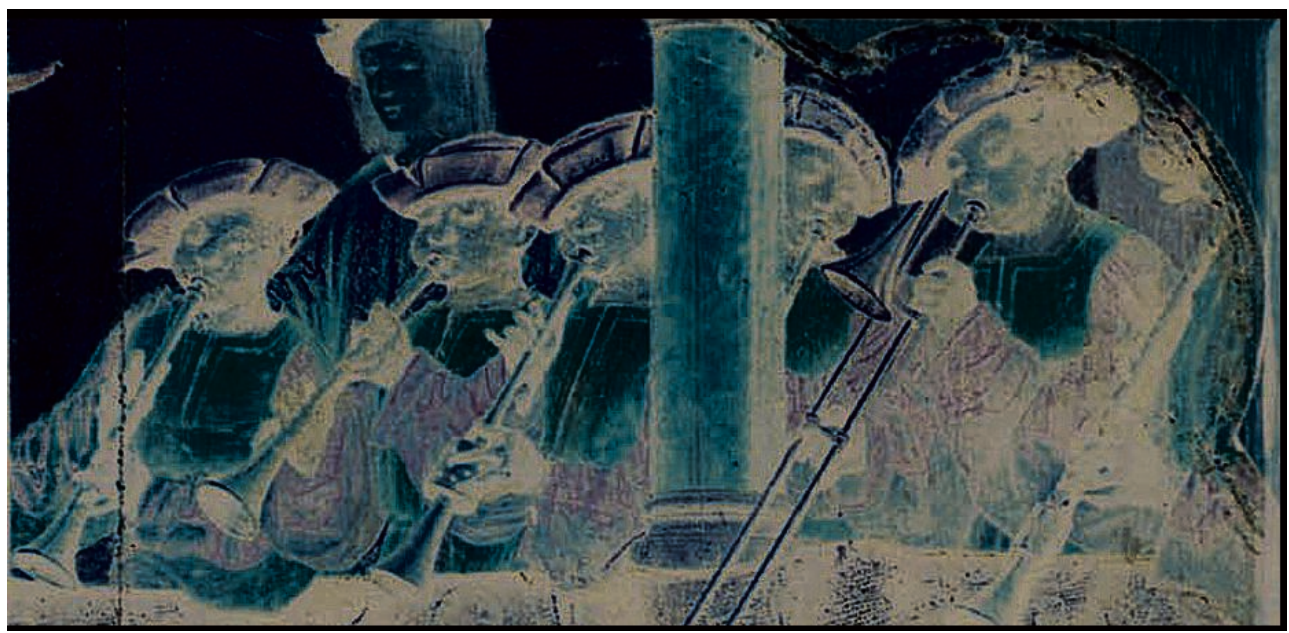

Cristóvão de figueredo, aba lateral dos "Painéis de sta auta" do convento da madre de DEUS EM LISBOA. ÓLEO S/ MADEIRA, 1520

MUSEU NACIONAL DE ARTE ANTIGA, LISBOA 
Lopo Homem-Reinéis e Antonio de Holanda. Pormenor da folha do "Atlas Miller" representando a Terra Brasilis, ou Brasil

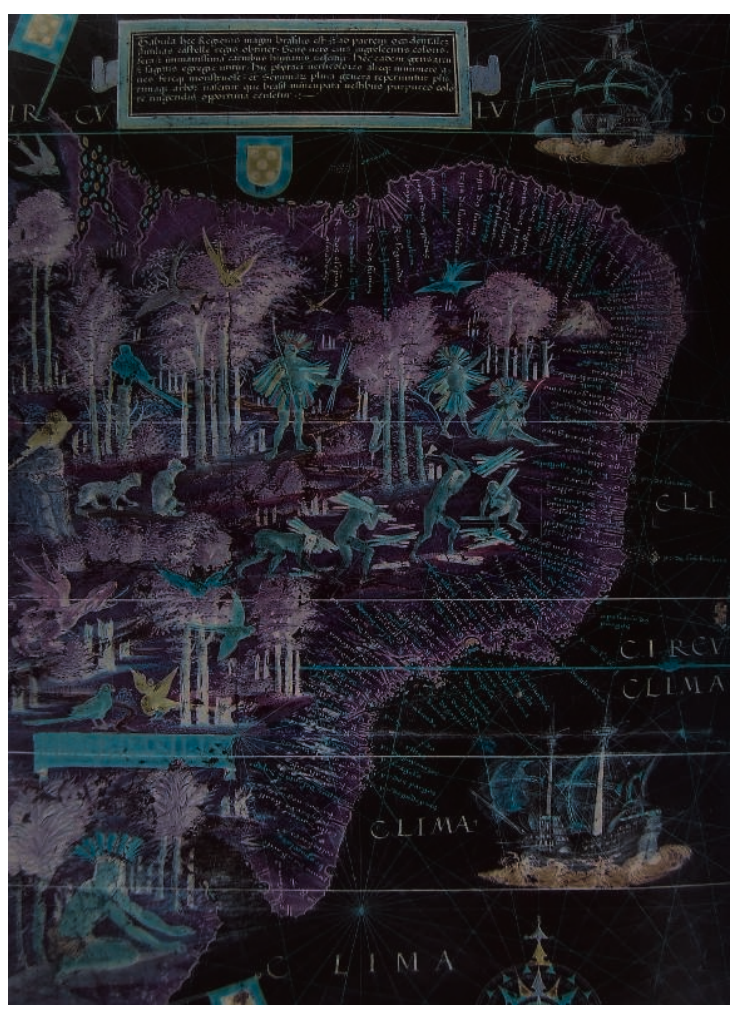

1519. PERgAMinho, $42 \times 60$ cMS.

BIBLIOTHĖQUE NATIONALE DE FRANCE, PARIS HTTP://gALLICA.BNF.FR/ARK:/12148/BTV1B55002607s

BIBLIOGRAFIA

AMARAL, Joaquim Ferreira do. "Pedro Reinel me fez". À Volta de um Mapa dos Descobrimentos, Lisboa: Quetzal Editores, 1995.

BARROS, João de. Décadas da Ásia, Livro II, cap. XII. $1^{a}$ ed., Lisboa, 1553: $4^{a}$ ed., introd. Hernâni Cidade, Lisboa, 1945.

BASSANI, Ezio. “Gli olifanti afro-portoghesi della Sierra Leone”, in Critica d'Arte, 163-165, Florença, 1979, pp. 175-201.

“Ivoires d'Afrique dans les anciennes collections françaises, Paris, Musée du Quai Branly, 2008.

"e FAGG, William. Africa and the Renaissance. Art in Ivory, New York-Munique, The Center for African Art, Prestel-Verlag, 1988.

BEN-AMOS, Paula. The Art of Benim, Londres, 1980.

CASTELO-BRANCO, Maria Teresa Schedel. A origem dos Reineis (mimeogr.), Lisboa, 1994. 
CORTESÃO, Armando. Cartografia e Cartógrafos Portugueses dos Sécs. XV e XVI, Lisboa, 1935.

“ e MOTA, A. Teixeira da. Portugaliae Monumenta Cartographica, 6 vols., Lisboa, 1960; $2^{\mathrm{a}}$ ed. aumentada, Lisboa, Imprensa Nacional/Casa da Moeda, 1987.

CORTESÃO, Jaime. Alexandre de Gusmão e o Tratado de Madri. Rio de Janeiro, Imprensa Nacional, 8 vols., 1950-60.

“. História da Cartografia do Brasil, Rio de Janeiro, Instituto Rio Branco, 1955.

COSTA, João Paulo Oliveira e. D. Manuel I, Lisboa, Temas \& Debates, 2008.

CURNOW, Katty. The Afro-Portuguese ivories: classification and stylistic analysis of a hybrid art form, tese de Doutorado, Indiana University, 1983.

DENUCÉ, Jean. Les Origines de la Cartographie Portugaise, Gand, 1908 (rep. Amsterdã, 1963).

FAGG, William. Afro-Portuguese ivories, Londres, British Museum, 1959.

FERNANDES, Valentim. 0 manuscrito de Valentim Fernandes, ed. António Baião, Lisboa, Academia Portuguesa da História, 1940.

FREYRE, Gilberto. O Mundo que o Português criou, Lisboa, 1940.

LEITE, Duarte. "O mais antigo mapa do Brasil", in História dos Descobrimentos. Coletânea de Esparsos, org. Vitorino Magalhães Godinho, Lisboa, Ed. Cosmos, 1962, vol II, pp. 11-123.

MARQUES, Alfredo Pinheiro. "L'Atlas Miller: un problème résolu. L' Histoire de l'Art dans la Cartographie Portugaise", in Revue de la Bibliothèque Nationale de France, 1994, pp. 53-7.

“, Atlas Miller, Barcelona, Moleiro Ed., 2006.

MOTA, Avelino Teixeira da. "Gli Avori africani nella documentazione portoghese dei secoli 15-17" in Africa, 30, 1975, pp. 580-89.

PEREIRA, Duarte Pacheco. Esmeraldo De Sirtu Orbis, ed. Epifânio da Silva Dias, Lisboa, 1905.

PINTO, Maria Helena Mendes. "Elementos para o estudo formal e decorativo de peças afroportuguesas", IV Simpósio Luso-Espanhol de História da Arte, Coimbra, 1988, pp. 153-87.

SANTOS, Reynaldo dos. O Estilo Manuelino, Lisboa, Academia Nacional de Belas-Artes, 1952.

SENOS, Nuno. O Paço da Ribeira, 1501-1581, Lisboa, Ed. Notícias, 2002.

VITERBO, F. de Sousa. Trabalhos Náuticos dos Portugueses (Sécs. XV-XVII), Lisboa, 2ª ed. 1988.

\section{RESUMOS}

Na côrte dos reis D. João II e D. Manuel I de Portugal, ponto de encontro de gentes de todas as raças e proveniências, os escravos negros da Senegâmbia e Guiné, batizados, instruídos e casados com criadas mestiças ou até brancas, formavam uma elite, em que os mais aptos poderiam especializar-se em variados ofícios, de criados da alta nobreza a músicos e artistas. De 1470-80 até c.1540, distinguiu-se um grupo de habilíssimos entalhadores de marfim da Serra Leoa, criadores da arte híbrida chamada "afro-portuguesa" - primeiro exemplo duma arte colonial de origem europeia desde os Fenícios e Romanos... Pela sua inteligência no desenho e alta capacidade técnica, os filhos recebiam educação na escola do Paço, eram libertos e podiam seguir uma profissão liberal. Deve ter sido esse o caso de Pedro Reinel, ou "reinol" (i.e, já nascido no Reino), e seu filho Jorge, formados nas Matemáticas e Cosmografia, que viriam a tornar-se os fundadores e melhores representantes da "escola" de Cartografia manuelina. A esses dois negros oriundos da 
Serra Leoa devemos a primeira representação detalhada e realista do litoral do Brasil, e uma imagem mítica do seu interior.

In the court of kings John II (1481-95) and Manuel I (1495-1521) of Portugal, a melting pot of people of all races and origins, African slaves from Senegambia and Guinea, baptized, instructed and married to Portuguese women, of mixed blood or white, formed a true elite, where the most qualified could specialize in many crafts, up to musicians and artists. From 1470/80 till c.1540, a group of extremely skilled ivory carvers brought from Sierra Leone became distinguished, and created the "afro-portuguese" art (that we prefer to call "sapi-manueline"), the earliest example of an hybrid art of European origin since the Romans. Thanks to their intelligence in drawing and very high technical expertise, their sons could receive an education in the Palace School, be free and become liberal professionals. It must have been the case of Pedro Reinel, or "reinol" (i.e., born in the Realm) and his son Jorge, who received the best instruction in Mathematics and Cartography, eventually becoming the founders and greatest names of Manueline cartographic school. To these two negroes from Sierra Leone we owe the first detailed, realistic representation of Brazil's coast, as well as a mythical image (based on Tupinambá informations) of its interior.

Dans la cour des rois Jean II (1481-95) et Manuel Ier (1495-1521) du Portugal, un point de rencontre de toutes races et origines, les esclaves noirs de Sénégambie et Guinée, baptisés, instruits et marries à des portugaises métisses ou même blanches, formaient une vraie élite, où les plus qualifiés pouvaient se spécialiser en plusieurs métiers, jusqu'à devenir musiciens ou des artistes. Dès 1470/80 jusqu'à vers 1540 un groupe s'est distingué: de très habiles tailleurs d'ivoire provenant de Sierra Leone, qui ont créé l'art hybride "afro-portugais" (que nous préférons appeler "sapi-manuéline"), premier exemple d'un art colonial d'origine européenne depuis les Romains. Par son intelligence du dessin et énorme capacité technique, leurs fils recevaient une éducation à l'École du Palais, devenaient libres et pouvaient suivre une profession libérale. Ce soit avoir été le cas de Pedro Reinel, ou "reinol" (c'est-à-dire, né au Royaume), et son fils Jorge, formés en Mathématiques et Cartographie, qui deviendraient les fondateurs et plus grands représentants de l'École cartographique manuéline. À ces deux noirs originaires de Sierra Leone, mais portugais, l'on doit la plus ancienne représentation détaillée et réaliste de la côte du Brésil, ainsi qu'une image mythique (basée sur les informations de Tupinambás) de son intérieur.

En la corte de los reyes D. João II (1481-95) y D. Manuel (1495-1521) de Portugal, encrucijada de gente de todo el mundo, los esclavos negros de Senegambia y Guinea, después de bautizados, instruidos y casados con mujeres portuguesas, mestizas o blancas, eran una verdadera elite, donde los más hábiles podrían especializarse en variados oficios y hacerse hasta músicos o artistas. De 1470/80 hacia c.1540 viene a distinguirse un grupo de habilidosos entalladores de marfil de Sierra Leoa, que crean el arte híbrido "afro-portugués" (que preferimos llamar "sapimanuelino"), primer ejemplo de un arte colonial de origen europeo desde Roma. Por su inteligencia del dibujo y alta capacidad técnica, sus hijos han sido educados en la Escuela del Pazo, hechos libres, y siguieron una profesión liberal. Ha sido sin duda este el caso de Pedro Reinel, o "reinol" (esto és, nascido nel Reino) y de su hijo Jorge, formados en las Matemáticas y la Cartografía, que vendrían a ser los fundadores de la Escuela cartográfica manuelina y sus mejores representantes. A esos dos negros oriundos de Sierra Leona, pero portugueses, se debe la primera representación detallada y realista de la costa de Brasil y una imagen mítica (basada en los informes de Tupinambás) de su interior. 
ÍNDICE

Índice geográfico: Portugal, África, Brasil, Serra Leoa

Palavras-chave: Serra Leoa, marfins afro-portugueses, Atlas Miller, Ilha-Brasil

Palabras claves: Serra Leoa, marfins afro-portugueses, Atlas Miller, Ilha-Brasil Índice cronológico: 1504-1560

Keywords: Sierra Leone, African-Portuguese ivories, Atlas Miller, Brazil Island Mots-clés: Sierra Leone, ivoires afro-portugais, Atlas Miller, Île Brésil

\section{AUTOR}

\section{RAFAEL MOREIRA}

Departamento de História da Arte Universidade Nova de Lisboa 